\title{
PENGGUNAAN MEDIA OBJEK UNTUK MENINGKATKAN HASIL BELAJAR IPA PESERTA DIDIK
}

\author{
Miftahurrizqi \\ Masroah \\ Universitas Muhammadiyah Palangka raya
}

\begin{abstract}
Abstrak: Penelitian ini bertujuan untuk mengetahui keberhasilan penggunaan media objek dilihat dari hasil belajar peserta didik kelas V SDN-6 Langkai Palangkaraya Tahun Pelajaran 2012/2013 dan melihat apakah ada peningkatan hasil belajar peserta didik dengan menggunakan media objek yang sebelumnya masih dibawah nilai ketuntasan minimal belajar (KKM). Metode penelitian yang digunakan dalam penelitian ini adalah penelitian tindakan kelas (PTK). Populasi penelitian berjumlah 22 orang peserta didik yang sekaligus dijadikan sampel penelitian. Teknik analisis data yang digunakan untuk menghitung keberhasilan belajar peserta didik menggunakan rumus persentase yaitu $P=\frac{F}{N} X 100 \%$ dimana melihat peningkatan dari siklus I dan siklus II. Hasil penelitian menunjukan bahwa : penggunaan media objek sangat efektif untuk meningkatkan hasil belajar IPA peserta didik kelas V SDN-6 Langkai Palangkaraya Tahun Pelajaran 2012/2013. Hasil ini dapat dibuktikan dengan perolehan nilai rata-rata setiap siklus semakin meningkat. Pada siklus I nilai rata-rata yang diperoleh adalah 77,27\% dengan kategori baik tapi masih ada peserta didik yang belum tuntas dan akan dilanjutkan pada siklus II hasil belajar IPA peserta didik terlihat sangat meningkat dengan perolehan nilai rata-rata $86,81 \%$ pada kategori sangat baik.
\end{abstract}

Kata kunci: $\quad$ Media,Objek, IPA.

\section{PENDAHULUAN}

Ilmu Pengetahuan Alam (IPA) merupakan salah satu mata pelajaran yang berhubungan tentang alam secara sistematis, sehingga IPA bukan hanya penguasaan kumpulan pengetahuan yang berupa fakta-fakta, konsep-konsep atau prinsip-prinsip saja, tetapi merupakan suatu proses penemuan. Salah satu cara untuk memudahkan proses pembelajaran IPA yaitu menggunakan suatu metode ceramah, guru lebih baik menggunakan metode yang bervariasi seperti menggunakan media pembelajaran agar kegiatan belajar-mengajar tidak membosankan, dan menarik perhatian peserta didik.

Benda-benda nyata dapat memegang peran penting dalam upaya memperbaiki proses pembelajaran. Menggunakan media benda nyata dalam pembelajaran lebih efektif, dalam menampilkan benda-benda nyata tentang ukuran, suara, gerak-gerik, permukaan bobot badan, bau serta manfaatnya

Benda-benda nyata ini banyak macamnya, mulai dari benda dan mahluk hidup seperti binatang dan tumbuhtumbuhan, juga termasuk benda-benda mati misalnya batuan, air, tanah, dan lainlain. Peneliti ingin menerapkan media objek pada proses pembelajaran dikarenakan agar lebih efektif dan memudahkan peserta didik untuk memahami materi yang akan disampaikan.

Berdasarkan hasil observasi yang dilakukan di kelas V SDN - 6 Langkai Palangkaraya Tahun Pelajaran 2012/2013 pada proses pembelajaran IPA guru tidak menggunakan media objek sehingga situasi pembelajaran menjadi kurang menyenangkan dan membuat peserta didik 
menjadi jenuh. Peserta didik tidak termotivasi untuk mengikuti proses pembelajaran IPA yang mengakibatkan tujuan pembelajaran tidak tercapai secara optimal. Hal ini dibuktikan dengan rendahnya hasil belajar IPA peserta didik yaitu dari peserta didik yang berjumlah 22 orang, hanya $31,8 \%$ atau 7 peserta didik yang mendapatkan nilai ketuntasan minimal belajar. Sisanya $68,2 \%$ atau 15 orang peserta didik masih mendapatkan nilai dibawah ketuntasan minimal belajar. Sedangkan ketuntasan minimal belajar atau KKM yang ditetapkan sekolah untuk mata pelajaran IPA yaitu nilai 65 .

Hal ini disebabkan karena salah satunya guru tidak menggunakan media objek terhadap proses pembelajaran IPA dan media yang disampaikan oleh guru tidak efektif dan tidak menarik perhatian peserta didik sehingga mereka tidak termotivasi karena tidak melihat bendanya langsung dan membuat pemahaman peserta didik masih kurang terhadap materi yang disampaikan. Salah satu cara untuk mengatasi permasalahan tersebut yaitu dengan cara memperbaiki proses pembelajaran IPA dengan menggunakan media pembelajaran objek untuk meningkatkan pemahaman peserta didik terhadap materi yang disampaikan.

\section{METODOLOGI}

Penelitian ini dilaksanakan di SDN 5 Pahandut Palangkaraya pada semester ganjil tahun ajaran 2012 /2013. Yang beralamat di jalan Pepaya Palangka Raya.

Metode penelitian eksperimen yang digunakan adalah model Randomized Subject pretest posttest control group Design. Dalam model ini kita harus menentukan dua kelas, yang pertama kelas eksperimen1 dan yang kedua adalah Kelas Eksperimen2. Dimana kelas experimen1 akan mendapatkan pembelajaran dengan menggunakan media konkret sebagai media pembelajarannya. Sedangkan pada Kelas Eksperimen2 menggunakan media gambar sebagai media pembelajarannya.
Eksperimen menurut Arikunto (3013:3) adalah suatu cara untuk mencari sebap akibat (hubungan kausal) antara dua faktor yang sengaja ditimbulkan oleh peneliti dengan mengurangi atau menyisihkan faktor-faktor lain yang bisa mengganggu. 'Dalam penelitian eksperimen ada perlakuan (tratmen) metode penelitian digunakan untuk mencari pengaruh perlakuan tertentu terhadap yang lain dalam kondisi yaang terkendali (sugiono, 2013:72).

Populasi merupakan sekumpulan objek sejenis yang menjadi target generalisasi penelitian. Pendapat tersebut sesuai dengan pendapat Nurul Zuriah (2009:116) yang mengatakan bahwa "populasi adalah seluruh data yang menjadi perhatian peneliti dalam suatu ruang lingkup dan waktu yang ditentukan".

Pendapat ahli maka dapat disimpulkan bahwa populasi adalah keseluruhan dari objek yang akan diteliti. Maka populasi penelitian disini adalah seluruh peserta didik kelas VI A dan VI B SDN 5 Pahandut Palangka Raya tahun ajaran 2012/ 2013 yang berjumlah 40 orang. Pengumpulan data merupakan salah satu bagian yang penting dalam suatu penelitian. Untuk mengumpulkan data penelitian, maka teknik yang digunakan dalam penelitian ini adalah Tes. Tes disini digunakan untuk mengukur aspek kognitif peserta didik.

Kata media berasal dari bahasa latin yang secara harfiah berarti tengah, perantara, atau pengantar, pesan dari pengirim kepada penerima pesan. Media merupakan semua bentuk perantara yang digunakan oleh manusia untuk menyampaikan atau menyebarkan ide, gagasan atau pendapat yang dikemukakan itu sampai kepada penerima. Menurut Jennah, (2009:1).

Menurut Rudi Susilana dan Cepi Riyana (2007:22) menyatakan bahwa "Objek merupakan media tiga dimensi yang menyampaikan informasi tidak dalam bentuk penyajian, melainkan dari bentuk fisiknya sendiri, seperti ukurannya, bentuk 
beratnya, susunannya, warnanya, fungsinya, dan sebagainya".

Media memiliki peran yang sangat penting dalam dunia pendidikan. Karena media dapat memperjelas apa yang dipelajari oleh peserta didik. Media merupakan perantara dalam menyampaikan materi pelajaran agar lebih mudah dipahami dan dimengerti oleh peserta didik. Media objek memiliki fungsi yang sama dengan fungsi media pada umumnya.

Pada proses pembelajaran dalam menggunakan media tentu harus terdapat langkah-langkah yang harus diperhatikan dalam menggunakannya. Begitu juga dalam menggunakan media objek sehingga tujuan yang ingin dicapai dengan digunakan media tersebut dalam pembelajaran dapat dicapai dengan baik.

Hasil belajar merupakan taraf keberhasilan peserta didik dalam mempelajari materi pelajaran di sekolah yang dinyatakan dalam bentuk skor perolehan hasil tes dari sejumlah materi pelajaran tertentu. Menurut Sudjana (2006:22) "Hasil belajar adalah kemampuan-kemampuan yang dimiliki peserta didik setelah ia menerima pengalaman belajar". Sedangkan menurut Hamalik (2006:30) bahwa "Hasil belajar adalah bila seseorang telah belajar akan terjadi perubahan tingkah laku pada orang tersebut, misalnya dari tidak tahu menjadi tahu, dari tidak mengerti menjadi mengerti". Kegiatan belajar mengajar adalah suatu kondisi yang sengaja diciptakan oleh guru, dimana guru sebagai pengajar dan peserta didik sebagai peserta didik yang mengikuti pembelajaran. Menurut Hamalik, (2007:52) menyatakan "Pembelajaran merupakan aktivitas yang paling utama dalam kegiatan belajar mengajar".

pesawat sederhana diperlukan bukan untuk menciptakan gaya. Pesawat sederhana digunakan untuk memudahkan pelaksanaan pekerjaan, walaupun membutuhkan waktu yang lebih lama (lintas yang lebih jauh). Pesawat sederhana dikelompokan menjadi empat jenis, yaitu tuas (pengungkit), bidang miring, katrol dan roda.

Media pembelajaran IPA sangat berpengaruh terhadap hasil belajar IPA peserta didik, maka melalui media pembelajaran yaitu media objek yaitu media tiga dimensi yang menyatakan informasi tidak dalam bentuk penyajian, melainkan dari bentuk fisiknya sendiri, seperti ukurannya, bentuk, beratnya, susunannya warnanya, serta fungsinya. Dimana media objek merupakan media sebenarnya. Benda yang nyata dapat memegang peran penting dalam upaya memperbaiki proses pembelajaran.

\section{HASIL DAN PEMBAHASAN}

Penelitian ini dilaksanakan di SDN-6 Langkai Palangkaraya yang terletak di jalan RTA. Milono KM 3,5. Khususnya pada kelas $\mathrm{Vb}$ Tahun Pelajaran 2012/2013. Adapun alasan peneliti melakukan penelitian di sekolah ini adalah peneliti menilai lokasi tersebut layak untuk di jadikan objek penelitian karena atas dasar masalah-masalah yang terkait dengan variabel penelitian.

Metode yang digunakan dalam penelitian ini adalah penelitian tindakan kelas (PTK) yaitu studi terhadap praktik pembelajaran di kelas dengan tujuan memperbaiki dan meningkatkan kualitas proses pembelajaran di kelas dengan tujuan memperbaiki dan meningkatkan kualitas proses pembelajaran dengan melakukan tindakan tertentu. Jenis penelitian yang digunakan adalah Penelitian Tindakan Kelas (PTK), dimana peneliti terlibat langsung dalam penelitian sejak awal sampai dengan hasil penelitian (dalam Subiyati, 2008).

Menurut Kemmis dan MC Taggart: "Model untuk kerja yang dilakukan dalam penelitian ini adalah model proses dalam bentuk 2 (dua) siklus".

\section{Tabel 1. Hasil Analisis Pre-test subjek penelitian:}


Kelas A (Pre)

\begin{tabular}{|c|c|c|c|c|}
\hline \multirow[b]{2}{*}{$\begin{array}{l}\mathrm{N} \\
\mathrm{o}\end{array}$} & \multirow[b]{2}{*}{$\begin{array}{c}\text { Nama } \\
\text { Peserta } \\
\text { didik }\end{array}$} & \multirow[b]{2}{*}{ Nilai } & \multicolumn{2}{|c|}{ Ketuntasan } \\
\hline & & & $\underset{\text { Tuntas }}{\geq 65}$ & $\begin{array}{c}<65 \\
\text { Tidak Tuntas }\end{array}$ \\
\hline 1. & HKL & 35 & - & $\sqrt{ }$ \\
\hline 2. & ARL & 40 & - & $\sqrt{ }$ \\
\hline 3. & ZSA & 55 & - & $\sqrt{ }$ \\
\hline 4. & SJ & 50 & - & $\sqrt{ }$ \\
\hline 5. & AJK & 65 & $\sqrt{ }$ & - \\
\hline 6. & MI & 55 & - & $\sqrt{ }$ \\
\hline 7. & GHY & 50 & - & $\sqrt{ }$ \\
\hline 8. & MR & 45 & - & $\sqrt{ }$ \\
\hline 9. & $\overline{\mathrm{AR}}$ & 55 & - & $\sqrt{ }$ \\
\hline $\begin{array}{l}1 \\
0 .\end{array}$ & $\overline{\mathrm{AS}}$ & 40 & - & $\sqrt{ }$ \\
\hline $\begin{array}{l}1 \\
1 .\end{array}$ & FTR & 35 & - & $\sqrt{ }$ \\
\hline $\begin{array}{l}1 \\
2 .\end{array}$ & MZA & 65 & v & - \\
\hline $\begin{array}{l}1 \\
3 .\end{array}$ & RDD & 65 & $\sqrt{ }$ & - \\
\hline $\begin{array}{l}1 \\
4 .\end{array}$ & MKW & 50 & - & $\sqrt{ }$ \\
\hline $\begin{array}{l}1 \\
5 .\end{array}$ & SAB & 45 & - & $\sqrt{ }$ \\
\hline $\begin{array}{l}1 \\
6 .\end{array}$ & NDF & 35 & - & $\sqrt{ }$ \\
\hline $\begin{array}{l}1 \\
7 .\end{array}$ & MRK & 25 & - & $\sqrt{ }$ \\
\hline 8. & AR & 45 & - & $\sqrt{ }$ \\
\hline 9. & $\overline{\mathrm{AM}}$ & 50 & - & $\sqrt{ }$ \\
\hline $\begin{array}{l}2 \\
0 .\end{array}$ & UL & 50 & - & $\sqrt{ }$ \\
\hline $\begin{array}{l}2 \\
1 .\end{array}$ & MI & 25 & - & $\sqrt{ }$ \\
\hline $\begin{array}{l}2 \\
2 .\end{array}$ & ER & 45 & - & $\sqrt{ }$ \\
\hline & Jumlah & 1025 & 3 & 19 \\
\hline & Rata-rata & 46,59 & & \\
\hline & ersentasi & & $13,63 \%$ & $86,36 \%$ \\
\hline
\end{tabular}

Pada tabel hasil tes awal (pre test) siklus I pra tindakan terlihat dari nilai hasil belajar peserta didik kelas Vb SDN 6 Langkai Palangkaraya dengan rata-rata 46,59 termasuk dalam kriteria kurang tercapai. Sehingga pada tes awal/pra tindakan dalam ketetapan tingkat ketercapaian keberhasilan pembelajaran belum memenuhi syarat ketuntasan belajar.

Tabel 2. Hasil Analisis Post Test subjek penelitian:

\begin{tabular}{|c|l|c|c|c|}
\hline \multirow{2}{*}{ No } & \multirow{2}{*}{$\begin{array}{c}\text { Nama } \\
\text { Peserta } \\
\text { didik }\end{array}$} & Nilai & \multicolumn{2}{|c|}{ Ketuntasan } \\
\cline { 4 - 5 } & & 65 & $\begin{array}{c}\geq 65 \\
\text { Tuntas }\end{array}$ & $\begin{array}{c}\text { Tidak } \\
\text { Tuntas }\end{array}$ \\
\hline 1. & HKL & 70 & $\checkmark$ & - \\
\hline 2. & ARL & 60 & - & $\checkmark$ \\
\hline 3. & ZSA & 65 & $\checkmark$ & - \\
\hline 4. & SJ & 80 & $\checkmark$ & - \\
\hline 5. & AJK & 80 & $\checkmark$ & - \\
\hline 6. & MI & 75 & $\checkmark$ & - \\
\hline 7. & GHY & 70 & $\checkmark$ & - \\
\hline 8. & MR & 85 & $\checkmark$ & - \\
\hline 9. & AR & 70 & $\checkmark$ & - \\
\hline 10. & AS & 60 & - & $\checkmark$ \\
\hline 11. & FTR & 60 & - & $\checkmark$ \\
\hline 12. & MZA & 80 & $\checkmark$ & - \\
\hline 13. & RDD & 80 & $\checkmark$ & - \\
\hline 14. & MKW & 70 & $\checkmark$ & - \\
\hline 15. & SAB & 75 & $\checkmark$ & - \\
\hline 16. & NDF & 80 & $\checkmark$ & - \\
\hline 17. & MRK & 70 & $\checkmark$ & - \\
\hline 18. & AR & 80 & $\checkmark$ & - \\
\hline 19. & AM & 80 & $\checkmark$ & - \\
\hline 20. & UL & 70 & $\checkmark$ & - \\
\hline 21. & MI & 60 & - & $\checkmark$ \\
\hline 22. & ERS & 60 & - & $\checkmark$ \\
\hline Jumlah & 1575 & 17 & 5 \\
\hline Rata-rata & 71,59 & & $22,72 \%$ \\
\hline Presentase & & $77,27 \%$ & \\
\hline & & & & \\
\hline
\end{tabular}

Pada tabel hasil tes awal ( Pre Test ) pra tindakan terlihat dari nilai hasil belajar peserta didik kelas Vb SDN 6 Langkai Palangkaraya dengan rata-rata 71,59 termasuk dalam kriteria cukup tercapai. Sehingga pada tes siklus I dalam ketetapan tingkat ketercapaian keberhasilan pembelajaran sedah memenuhi syarat ketuntasan belajar, tapi masih ada beberapa peserta didik yang mendapatkan nilai rendah.

Berdasarkan data yang diperoleh, hasil belajar pada siklus II telah mencapai nilai kriteria ketuntasan minimal belajar (KKM) kuantitatif yaitu 86,81. Hasil ini telah melampaui KKM keberhasilan pembelajaran untuk mata pelajaran IPA yang diharapkan untuk peserta didik adalah $\geq 65$. Hasil tes yang telah dilakukan menunjukan bahwa dari 22 orang peserta didik ada 7 orang peserta didik yang mendapat nilai 90, dan 2 orang peserta didik mendapat nilai 95 , serta 3 orang mendapat nilai 80 dan 10 orang peserta didik mendapat nilai 85 . 


\section{PENUTUP}

Hasil penelitian disimpulkan bahwa penggunaan media objek pada mata pelajaran IPA lebih efektif untuk meningkatkan hasil belajar IPA peserta didik kelas V SDN-6 Langkai Palangkaraya Tahun Pelajaran 2012/2013.

Pada siklus pertama peneliti menggunakan media objek pada mata pelajaran IPA materi pesawat sederhana hanya banyak mempelajari materi pesawat sederhana secara umumnya terdiri dari tuas, katrol bidang miring dan roda sehingga peserta didik tidak memahami apa saja perbedaan tuas golongan I, II, dan III sehingga membuat masih ada dibawah ketuntasan minimal belajar IPA dengan rata-rata 71,59 dengan persentase 77,27 pada siklus I, karena hasil belajar secara klasikal pada siklus I masih dibawah dibawah $85 \%$ maka akan dilanjutkan pada siklus II.

Berdasarkan data yang diperoleh, hasil belajar pada siklus II telah mencapai nilai kriteria ketuntasan minimal belajar (KKM) kuantitatif yaitu 86,81 dengan persentase $100 \%$ dan sudah meningkat secara klasikal, maka penggunaan media objek lebih efektif digunakan untuk meningkatkan hasil belajar IPA peserta didik.

\section{DAFTAR PUSTAKA}

Anggoro,dkk,(2007),Media

Penelitian,Jakarta: Universitas Terbuka.

Arsyad,A.,(2003), Media Pembelajaran,Jakarta: PT.Raja Grafindo Persada.

Burhan, Bungin.,(2004),Metodologi

Penelitian Kuantitatif,Jakarta: kencana.

Departemen Pendidikan Nasional,(2004),Kurikulum

Standar Kompetensi, Jakarta: Departemen Pendidikan Nasional
Dewiki \& Yuniati,(2006), Ilmu Alamiah

Dasar,Jakarta: Universitas Terbuka.

Hasbullah,(2006),Dasar-dasar Ilmu Pendidikan,Jakarta: PT. Raja Grafindo Persada.

$\begin{array}{cr}\text { Hadeli,(2006), Metode } & \text { Penelitian } \\ \text { Kependidikan, } & \text { Ciputat: } \\ \text { Quantum Teaching } & \end{array}$

Hamalik,O.,(2006), Perencanaan

Pembelajaran Berdasarkan

Pendekatan Sistem, Jakarta: PT.

Bumi Aksara

Haryanto,(2007), Sains untuk SD Kelas $V$,Jakarta: PT. Gelora Aksara Pratama

Iskandar,(2008),Metodologi Penelitian pendidikan dan Sosial (Kuantitatif dan Kualitatif), Jakarta: Gaung Persada Press (GP Press).

Jennah,Raudatul.,(2009),Media

Pembelajaran, Banjarmasin: Antasari Press.

Kadir,(2010),Statistika Untuk Penelitian Ilmu-Ilmu Sosial, Jakarta: PT. Rosemata Sampurna.

Masitah,(2012),Efektifitas Penggunaan Media Untuk Meningkatkan Hasil Belajar IPA Peserta didik kelas IV SDN Telang Gemilang Kabupaten Barito Selatan Tahun Pelajaran 20011/2012. Palangkaraya: Universitas Muhammadiyah. Tidak dipublikasikan.

Margono,(2003),Metodologi Penelitian Pendidikan, Jakarta: Rineka Cipta Syamsudin Makmur Abin, (2003). Psikologi 
Kependidikan Perangkat Sistem Pengajaran Modul, Bandung : PT. Remaja Rosdakarya

Nasution,(2003), Metodologi Penelitian Ilmiah. Jakarta: Bumi Aksara

Sardiman,Arief.,(2005),Media Pendidikan, Pengertian, Pengembangan dan Pemanfaatannya Jakarta: PT. Raja Grafindo Persada.

Sudjana,Nana \& Rivai,Ahmad.,(2002), Media Pengajaran. Bandung: PT. Remaja Rosdakarya.

Sudjana,Nana.,(2006), Penilaian Hasil Proses Belajar Mengajar, Bandung: PT.

Remaja Rosdakarya.

Syamsudin,Makmur,A.,(2003),Psikologi Kependidikan Perangkat Sistem Pengajaran Modul, Bandung: PT. Remaja Rosdakarya

Setiawati,Rica.,(2011), Efektivitas Penggunaan Media Obyek Pada Pembelajaran SAINS Terhadap Motivasi Belajar Peserta Didik Kelas III SDN Tumbang Pariye Tahun Pelajaran 2010/2011. Palangkaraya: Universitas Muhammadiyah. Tidak dipublikasikan.

Simponi,(2010), Pengaruh Penggunaan Metode Demonstrasi Terhadap Prestasi Belajar Peserta Didik, Palangka Raya: Universitas Muhammadiyah Palangkaraya.

Sukardi,(2003),Metodologi Penelitian Pendidikan, Jakarta: PT. Bumi Aksara.

Sugiyono,(2009),Metodologi Penelitian Pendidikan, Pendekatan Kuantitatif, Kualitatif, dan $R \& D$. Bandung: Alfabeta.
,(2006),Statistik

Untuk Penelitian, Bandung: Alfabeta

Sardiman,Ari.,(2007),Media Pendidikan. Jakarta: Raja Grafindo Persada

Suharhimi,Arikunto.,(2006), Dasar-Dasar Evaluasi Penelitian,Jakarta: PT. Bumi Aksara

$\begin{array}{lr}\text {,(2006),Dasar-Dasar } & \text { Evaluasi } \\ \text { Pendidikan,Jakarta: } & \text { Bumi } \\ \text { Aksara } & \end{array}$

Sudijono,Anas.,(2010),Pengantar Statistik Pendidikan,Jakarta: PT. Raja Grafindo 